\title{
Comunicación de malas noticias: perspectivas desde la anestesiología
}

\author{
How to tell bad news in anesthesiology
}

Laura Silvera1, Martín Pérez De Palleja², Carlos Álvarez ${ }^{3}$

\begin{abstract}
Objective: To learn communication skills, as they can have a positive impact on both the donor and the recipient of the bad news. To know, to improve and to reinforce the techniques of transmission of bad news. The communication of bad news is an inherent practice of the medical act, although normally we do not face as anesthetists, it is one of the most difficult tasks to which we are exposed. Not being prepared for it can compromise the human and technical skills we need to do it correctly, which is fundamental in conjunction with maintaining an adequate patient medical relationship. Paternalistic medicine has ceased to be such, to give rise to new forms of models of care, with an emphasis on the opinion and participation of the patient in decision making. To transmit bad news in an inadequate way, that is to say, drastically and without empathizing with the situation that the patient lives, causes the doctor to perform this task in a rude and erratic way. Approaching a person or a family with bad news, without a suitable plan to present the information in a structured way, is almost a guarantee that will generate more emotional pain and alteration of the news recipients. Conclusion: Most medical professionals have not been educated to give bad news, but almost all often face the fact. Hence the importance of being prepared for this responsibility, so we need training to do it properly and professionally.
\end{abstract}

\section{RESUMEN}

Objetivo: Desarrollar las habilidades de comunicación, dado que estas pue-

\section{Key words:}

Preparation, comunicatinn, bad news

Palabras clave:

Preparación, comunicación, malas noticias

\section{Anestesiólogo.}

2 Anestesiólogo. Asistente del Departamento de Anestesiología Universidad de la República. Fellow en Anestesia Obstétrica World Federation of Societies of Anesthesiologists.

3 Anestesiólogo. Profesor Agregado del Departamento de Anestesiología Universidad de la República Hospital de la Mujer. Departamento de Anestesiología, Facultad de Medicina Montevideo, Uruguay.

Fecha de recepción: 11 de abril de 2019

Fecha de aceptación: 12 de abril de 2019

\section{ORCID}

https://orcid.org/0000-0002-2935-4545

\section{Correspondencia:}

Dr. Martín Pérez De Palleja

Email: perezdepalleja@gmail.com 
den producir un impacto positivo tanto en el dador como en el receptor de malas noticias. Conocer, mejorar y reforzar las técnicas en la transmisión de malas noticias. La comunicación de malas noticias es una práctica inherente al acto médico, si bien no nos enfrentamos habitualmente como anestesiólogos, es una de las tareas más difíciles a las que estamos expuestos. El hecho de no estar preparados para ello puede comprometer las competencias que necesitamos para hacerlo adecuadamente, lo que es fundamental conjuntamente con el mantenimiento de una adecuada relación médico paciente. La medicina paternalista ha dejado de ser tal, para dar lugar a nuevas formas de modelos de atención, poniéndose énfasis en la opinión y participación del paciente (empoderamiento) en la toma de decisiones. Transmitir una mala noticia de forma inadecuada, es decir, de forma drástica y sin empatizar con la situación que vive el paciente, hace que el médico ejerza esa tarea de manera áspera y errática. Acercarse a una persona o una familia con una mala noticia, sin un plan adecuado para presentar la información en forma estructurada, es casi una garantía de que se generará mayor dolor emocional y la alteración de los receptores de la noticia. Conclusión: La mayoría de los profesionales médicos no han recibido educación para dar malas noticias, pero casi todos se enfrentan frecuentemente al hecho. De ahí la importancia de estar preparados para esta responsabilidad, por lo que necesitamos formación para hacerlo de manera adecuada y profesional.

\section{Introducción}

a comunicación de malas noticias es una práctica inherente al acto médico, si bien no nos enfrentamos habitualmente como anestesiólogos, es una de las tareas más difíciles a las que estamos expuestos.

El hecho de no estar preparados para ello puede comprometer las competencias técnicas y comunicacionales que necesitamos para hacerlo adecuadamente, lo que es fundamental conjuntamente con el mantenimiento de una adecuada relación médico paciente.

\section{¿Por qué necesitamos aprender a dar malas noticias?}

Las malas noticias forman parte de la práctica médica habitual, sin embargo, no hemos sido preparados para darlas, lo que sin duda perjudica la comunicación con el paciente y la familia.

Comunicar malas noticias es una de las tareas más difíciles que deben enfrentar los médicos, a pesar de lo cual ha sido considerada como una competencia menor.

¿Qué necesitamos hacer para aprender? El aprendizaje es un proceso de adquisición de conocimien- tos, habilidades y actitudes, que se ve posibilitado mediante el estudio, la enseñanza y/o la experiencia.

Para aprender se necesitan tres actos imprescindibles: observar, estudiar y practicar.

Para dicho proceso el requisito fundamental es enfrentarnos al problema, ya sea de forma real o simulada

\section{Discusión}

En la relación médico-paciente, es el médico el que habitualmente aporta un porcentaje más elevado a la hora de la decisión sobre lo que dice y el cómo lo dice. Por otra parte cada médico tiene su propia filosofía al respecto, su propio sistema de creencias, su experiencia acumulada, y en muchos casos subconscientemente manejada.

Lamentablemente, los profesionales reciben poco o ningún adiestramiento en este sentido, durante su etapa de formación en las facultades.

La dificultad para comunicar las malas noticias principalmente se asoció al temor de la reacción del enfermo y/o la familia.

Podemos definir la mala noticia: como aquella que drástica y negativamente altera la propia perspectiva del paciente en relación con su futuro. Aquella 
que afecta negativamente la expectativa de las personas, bien por ser ella la directamente afectada por la enfermedad o por ser alguna persona de su entorno[1],[2].

En la relación médico-paciente es el médico el que, habitualmente, aporta un porcentaje más elevado a la hora de la decisión sobre lo que dice y cómo lo dice, en dependencia de su sistema de creencias y la experiencia acumulada[3].

Las habilidades comunicativas del médico son el complemento de su preparación científico-técnica y sus otras habilidades y destrezas. A través de éstas evita manifestaciones o expresiones que puedan ser interpretadas como incomprensión, indiferencia o subestimación, o, en el peor de los casos, que el paciente se sienta juzgado e insatisfecho. Las habilidades comunicativas en la relación médico-paciente, influyen en mejores resultados en la salud física, mental, funcional y subjetiva, en el nivel de satisfacción de pacientes y familiares.

Esquema de sistematización de pasos: los receptores de malas noticias no olvidan nunca dónde, cuándo y cómo se les informó de ella. Los factores que dificultan la comunicación de malas noticias pueden provenir del ambiente sociocultural, del paciente o del propio médico.

El paciente puede no querer saber la verdad, puede aceptar la realidad y pedirnos que no informemos a la familia de la enfermedad que padece ¿qué debemos hacer en esos casos? ¿Debemos obligarlo a conocer la verdad? ¿Debemos ignorar su solicitud y hablar con la familia?

Sin duda conociendo los derechos y obligaciones de nuestros pacientes, debemos actuar respetando los principios bioéticos que rigen la ética profesional médica.

En Uruguay, la Ley 18.335 de agosto de 2008 establece los Derechos y Obligaciones de los usuarios de los servicios de salud. Destacamos los artículos que se refieren a la información a la que tiene derecho el paciente y que son fundamentales para el tema que abordamos:

Artículo 11.- "Todo procedimiento de atención médica será acordado entre el paciente o su representante luego de recibir información adecuada, suficiente y continua- y el profesional de salud. El paciente tiene derecho a negarse a recibir atención médica y a que se le expliquen las consecuencias de la negativa para su salud..."

Artículo 18.-“Todo paciente tiene derecho a conocer todo lo relativo a su enfermedad. Esto comprende el derecho a:
A) Conocer la probable evolución de la enfermedad de acuerdo a los resultados obtenidos en situaciones comparables en la institución prestadora del servicio de salud.

B) Conocer en forma clara y periódica la evolución de su enfermedad que deberá ser hecha por escrito si así lo solicitase el paciente; así como el derecho a ser informado de otros recursos de acción médica no disponibles en la institución pública o privada donde se realiza la atención de salud.

En situaciones excepcionales y con el único objetivo del interés del paciente con consentimiento de los familiares se podrá establecer restricciones al derecho de conocer el curso de la enfermedad o cuando el paciente lo haya expresado previamente (derecho a no saber). Este derecho a no saber puede ser relevado cuando, a juicio del médico, la falta de conocimiento pueda constituir un riesgo para la persona o la sociedad.

C) Que los familiares $u$ otras personas que acompañen al paciente -ante requerimiento expreso de los mismos- conozcan la situación de salud del enfermo y siempre que no medie la negativa expresa de éste".

Algunos autores destacan la importancia que tiene la información honesta y clara al paciente, porque sin ella no tiene la capacidad de tomar decisiones, pierde la autonomía que es un principio bioético fundamental. "En algún momento a lo largo del proceso, los pacientes se enteran de lo que les ocurre y hablar de ello les permite compartir el sufrimiento y aliviarlo"[4].

La información requiere de la comunicación que es una herramienta fundamental e imprescindible en la relación médico paciente[5].

Comunicar es intercambiar mensajes entre individuos, donde se articulan múltiples elementos.

No solo se pone en juego la palabra, sino también la comunicación no verbal que incluye la mirada, la expresión, la postura, los gestos entre otras cosas. Todas estas características de la comunicación pueden determinar la eficacia del mensaje que se quiere transmitir.

Este mensaje debe ser claro, sencillo, breve, con palabras simples no coloquiales y orientado a un objetivo bien definido que el paciente y/o la familia comprendan[6].

El receptor, es aquella persona a quien va dirigida la comunicación.

El médico que dará la noticia debe estar preparado no solo para brindar la información en forma adecuada, sino para apoyar emocionalmente al paciente y a la familia, por tanto debe tener tiempo y no estar apurado. 
El doctor Gómez Sancho[7], médico anestesiólogo especialista en medicina paliativa, entre algunos de sus consejos está el de no dar nunca datos hasta no saber exactamente el diagnóstico, tener claro que ésta es una responsabilidad que corresponde exclusivamente al médico, que es precisamente el que cuenta con toda la información. Su estrecha relación con el paciente puede amortiguar el impacto de lo que se le comunique.

En relación a la familia, y considerando el 'paternalismo' o la mentira como prácticas desaconsejadas, el doctor Gómez Sancho alude a la pertinencia de la ley de Autonomía del Paciente de 2002, que aclara que el destinatario de la información debe ser el paciente y en todo caso las personas que éste, en exclusiva, autorice.

En cuanto a la forma en que se da la información, el autor propone dosificarla. Esto no supone ocultarla, sino no ceder a las presiones de la familia, con la que se debe trabajar para hacerles comprender actitudes que pueden ser perjudiciales para el paciente.

Además, señala Gómez Sancho, es crucial ser firme en el compromiso personal del médico con el paciente y la familia, expresando su apoyo incondicional.

Para concluir con una idea básica pero fundamental, el doctor afirma: "tan malo es callarse y mentir como dar toda la información brusca y sin hacerlo desde el punto de vista médico adecuadamente"[7].

Estudios aleatorizados han demostrado que el aprendizaje de habilidades de comunicación puede producir un impacto positivo tanto en el dador como en el receptor de malas noticias.

\section{¿Cómo abordar la comunicación de malas noticias?}

Así como las malas noticias pueden ser de muchos tipos, es decir, desde informar al paciente que tiene una enfermedad oncológica o una enfermedad crónica o que quedará con una secuela, o informar a un familiar la muerte de un integrante de la misma, el error en la administración de un fármaco o similar con la consecuente repercusión adversa, la forma de abordarlas también lo es.

De todas las áreas de la medicina, este proceso ha sido por excelencia una aportación importante de la oncología. Al igual que se utilizan en la práctica diaria protocolos de actuación para atender enfermedades complejas, los oncólogos Walter F. Baile, Robert Buckman y colaboradores, idearon un protocolo para comunicar malas noticias (Protocolo SPIKE: $\mathrm{S}=$ Setting the interview - ajuste de la entrevista-, $P=$ Perception -percepción sobre el paciente-, $I=$ invitation - inivitación-, $K=$ Knowledge -conocimiento- y, E = Emotions and empathic responses -emociones y respuesta empática-.

Este uso de este protocolo se ha extendido a todas las áreas de la medicina y de modo general nos invita a cumplir con las siguientes recomendaciones. Sin embargo, Buckman describió una serie de pasos que ayudan en este proceso[6],[7].

\section{Primera etapa. Preparar el entorno}

Es fundamental la privacidad, dejar que el paciente si así lo desea se encuentre acompañado por familiares o amigos. Permitirles que se sienten. Escuchar sin interrumpir, sin mostrar apuro, darle tiempo. Mantener los teléfonos en silencio.

En esta etapa se incluirían todos los aspectos relacionados con el momento más adecuado, lugar, profesional, paciente, etc., así como una pequeña evaluación del estado emocional del paciente para averiguar si es el momento más adecuado para dar la mala noticia.

\section{Segunda etapa. ¿Qué sabe el paciente?}

Antes de hablar, debemos saber qué es lo que percibe el paciente de su situación, qué es lo que sabe, este debe ser necesariamente el punto de partida. Esta fase es muy importante, ya que el paciente a menudo presenta ideas o al menos sospechas que pueden ahorrar mucho camino al profesional.

Se pueden hacer preguntas como ¿sabe que le está pasando? ¿En algún momento pensó que esto podía ser algo serio?

Puede suceder que aunque haya sido informado, el paciente haga una negación de la situación, que es un mecanismo de defensa o lo que en realidad quiere es comparar lo que se le va a decir ahora con lo que se le dijo previamente.

Con este tipo de preguntas podremos obtener información del paciente en diferentes aspectos:

- Cómo se acerca su impresión a la naturaleza real de su problema.

- Características del paciente: nivel educacional, capacidad de expresión, preparación, etc.

- Estado emocional en relación a su proceso. Conviene estar atento a lo que el paciente dice y a lo que no dice o evita decir, así como a todas las claves no verbales que seamos capaces de captar. Es interesante advertir la falta de concordancia entre comunicación no verbal y verbal. Es fundamental ver el lenguaje utilizado por el paciente, podemos estar ante alguien que nos dice "tengo algo en 
el pulmón "o frente a alguien que dice "tengo cáncer de pulmón".

Por otro lado, este tipo de preguntas en una persona que no sospeche nada pueden ayudar a aclimatarlo a la nueva situación.

Hay que tener en cuenta que el profesional no es el único medio de información. El paciente recibe información a través de otros enfermos, de medios diagnósticos o terapéuticos, de otros profesionales o de los medios de comunicación. Otra ventaja añadida de una correcta ejecución de esta fase es evitar los mensajes más o menos contradictorios que entre distintos profesionales se producen a menudo, ya sea por distinto criterio, por miedo a decir la verdad, por inseguridad o desconocimiento.

\section{Tercera etapa. ¿Qué quiere saber?}

Debemos intentar deducir hasta dónde quiere saber y no poner delante lo que nosotros pensamos que debe saber.

Puede suceder también que nos demos cuenta que no quiere saber y debemos dejar la puerta abierta para que cuando lo desee venga a hablar con nosotros, por ejemplo diciéndole "ahora no quiere hablar de este tema, está bien, me encontraré aquí, me avisa cuando lo desee y conversamos".

En cualquier caso, como ya se ha expresado anteriormente, no es necesario preguntarlo tan abiertamente para conocer si quiere y cuánto quiere saber un paciente. Una sensibilidad adecuada en el profesional puede obtener la misma información. En nuestra cultura, una opción puede ser la de esperar a que el enfermo sea el que nos pida más información, muy pendiente de la comunicación no verbal, esperando a que el paciente asimile cada "parte» de la información que se le haya dado con silencios y escucha activa, y que nos pida más mirando al profesional en actitud de espera o pidiendo más información con preguntas directamente.

Los deseos de información van cambiando habitualmente a lo largo del tiempo.

\section{Compartir la información}

No es fácil para el médico, pero tampoco lo es para el paciente. No puede darse toda la información junta, sino hacerlo de a poco para que el paciente pueda procesarlo. De pronto en ese momento quiere saber más del tratamiento que de la enfermedad en sí misma o quizá quiere saber todo. Pero a su vez, es fundamental asegurarnos que va entendiendo lo que le estamos diciendo, para ello es bueno detenerse, darle unos minutos y pedirle que nos explique con sus palabras lo que ha entendido, para así poder seguir.

\section{Responder a los sentimientos y reacciones del paciente}

En este punto se hace referencia a la empatía, a ponerse en el lugar del otro. Si no estamos dispuestos a apoyar al paciente, no debemos darle una mala noticia. Aquí el lenguaje no verbal es muy importante y pequeños gestos del médico, le dan seguridad al paciente como poner una mano sobre su brazo. Si se percibe que siente miedo, dudas o preguntas, hay que preguntarle ¿a qué teme?, en que lo puedo ayudar? podemos responder las preguntas que aparezcan o respetar su silencio.

\section{Estrategia de cuidados y seguimiento}

Luego de comunicar una mala noticia y valorar la reacción del paciente, debemos hablar de tratamiento, de las opciones y si las condiciones lo permiten, que pueda decidir.

En situaciones agudas (ej. politraumatizados, complicaciones intraoperatorias) se deben poner en práctica otro tipo de transmisión de información, sin dejar de lado lo aprendido anteriormente.

La primera información debe ser transmitida a la familia por un equipo, formado al menos por el cirujano (u otro médico responsable del paciente) y el anestesiólogo, en el que esté definido quién actuará como líder. El anestesiólogo responsable del caso puede encontrarse muy afectado, sobre todo si ha tenido lugar una reanimación sin éxito, y puede sentir la tentación de delegar en el otro facultativo la desagradable tarea de informar a la familia. En ningún caso se debe permitir que sea únicamente un facultativo el que informe a la familia. Si el anestesiólogo responsable del caso se encuentra muy abatido, podrá ser sustituido por el anestesiólogo que actúa como supervisor del incidente.

La información a la familia debe ser clara, respetuosa y ordenada. En primer lugar los facultativos que informen se identificarán con su nombre y categoría profesional. En segundo lugar se darán las peores noticias, puesto que se ha llamado inesperadamente a la familia y ésta espera que algo malo haya sucedido. A continuación se deben exponer los hechos conocidos, resaltando los intentos de reanimación realizados. La información debe ser la necesaria para explicar la condición del paciente y aquello necesario para explicar las decisiones que se adopten, debe atenerse a los hechos sin especular o establecer hipótesis que luego se puedan demostrar equivocadas. La familia debe saber que la información será actualizada y suministrada puntualmente. No se debe acusar a ningún miembro 
del personal, ni a razones de índole económica o administrativa. Las palabras error, negligencia, equivocación, inadvertido, fallo, accidente, etc., deben ser evitadas.

Puede ser útil dejar solos a los familiares durante unos minutos para que asimilen la información, y a continuación reanudar el encuentro, en el que se explicará con más detalle lo que aconteció en el quirófano u otra dependencia asistencial y se responderá a sus preguntas.

Si el paciente no ha fallecido, éste y/o su familia estarán completamente informados de todo lo que suceda en su evolución. Preferiblemente, y si las condiciones lo permiten, un anestesiólogo que no haya estado involucrado en el incidente se encargará de la relación con la familia, actuando como enlace entre ésta y el hospital. Esta relación a través de una sola persona reduce la posibilidad de confusiones y malas interpretaciones que se pueden producir cuando hay información que procede de varias fuentes. Además, se ofrecerá ayuda a la familia a través del asistente social y el equipo de psicología médica del hospital.

La familia del paciente en estado crítico sufre la angustia que supone la amenaza de la muerte inminente de su familiar, están bajo el impacto emocional de la pérdida brusca de la salud y apenas entienden lo imprevisible de su evolución clínica en cortos períodos de tiempo. Debemos estar conscientes de que, para la familia, el ingreso de su familiar a CTI o a cirugía es considerado a veces per se, como una pérdida[8].

El cumplimiento metódico del protocolo de BaileBuckman, en las áreas críticas, es una herramienta fundamental para lograr una comunicación afectiva y efectiva entre el trinomio médico - paciente - familia.

Con el fin de que el contenido de la información sea lo más coherente posible, se recomienda que sea el mismo médico el que informe de la evolución a la familia. También se debe tener especial énfasis en la oportunidad de la información médica, pues su falta, difícilmente justificable (generalmente se debe a que el personal se encuentra atendiendo aspectos técnicos de la atención, o a carga de trabajo excesiva), es una fuente obvia de ansiedad en los familiares ya de por sí angustiados.

Uno de los principales factores que provocan angustia en los familiares de pacientes quirúrgicos críticos es la incertidumbre; ésta debe ser manejada de forma clara, sensata, sutil y delicada, haciendo ver que los objetivos terapéuticos son modestos, a corto plazo, y no curas milagrosas e inmediatas, y que depende del resultado de éstos el cómo se reelabora dinámicamente el pronóstico a cada momento (se recomienda no crear esperanzas de mejoría sin funda- mento clínico).

Es también muy importante informar a la familia que existe un plan terapéutico a seguir y que la toma de decisiones sigue un orden lógico basado en las necesidades del paciente (hacer ver que nuestras decisiones no son erráticas), y que en caso de que los resultados no sean los esperados tenemos planes alternativos (siempre tomando las decisiones en conjunto con el paciente y sus familiares).

Todas las intervenciones terapéuticas urgentes que se planteen como es la intubación orotraqueal (ej. en paciente que se realizan procedimientos de sedación) la sujeción física por agitación, colocación de catéteres, etc., deberán ser comunicadas y explicadas detalladamente, pues la sorpresa que causan estas intervenciones en los familiares suelen ser, comprensiblemente, mal asumidas por los familiares y son fuente inminente de conflicto ético, moral y médicolegal.

Uno de los principales medios para abatir los conflictos médico - legales es precisamente la comunicación constante del médico sobre el estado de salud hacia los interesados, el siempre estar abierto al diálogo y brindar seguridad y confianza a todas las partes del proceso terapéutico.

La capacidad de decisión del paciente en estado crítico puede estar ausente (inconsciente, sedado) o estar disminuida por alteraciones fisiopatológicas concomitantes (hipoxia, acidosis, hipotensión, encefalopatía, etc.).

Esta situación hace a los familiares verse en la necesidad de intervenir en el proceso de toma de decisiones, pues es evidente que son los familiares los que mejor conocen las preferencias y deseos del paciente. En este contexto, una buena comunicación entre ambas partes es clave para la adecuada toma de decisiones[10].

\section{Conclusiones}

La mayoría de los profesionales médicos no han recibido educación para dar malas noticias, pero casi todos se enfrentan frecuentemente al hecho.

De ahí la importancia de estar preparados para esta responsabilidad, por lo que necesitamos formación para hacerlo de manera adecuada y profesional.

El proceso de comunicación de malas noticias es un evento angustiante para el trinomio médico - paciente - familia. Sin embargo, no debemos olvidar que ante todo debemos respetar la privacidad del paciente y sus familiares. La utilización de un enfoque humanístico y protocolizado como el elaborado por 
Baile-Buckman, y el aprendizaje de ciertas habilidades de comunicación pueden mejorar significativamente esta tarea. Lo que más le importa al paciente cuando recibe malas noticias es que el médico sea competente, honesto y atento con él; que permita que se le hagan las preguntas necesarias; que proporcione un diagnóstico concreto; y que use un lenguaje que pueda entender.

Más allá del enorme desafío que significa comu- nicar malas noticias, no debemos olvidarnos que este proceso se realiza en el período de máxima necesidad del paciente y sus familiares, por lo que no debemos perder la subjetividad, pero tampoco la objetividad. La ausencia de una de estas dos características nos hará desviarnos de nuestro objetivo y lastimar de un modo innecesario a quien confía su salud en nuestras manos. Sin duda, hay mucho por hacer y aprender al respecto.

\section{Referencias}

1. Buckman R. Breaking bad news: why is it still so difficult? Br Med J (Clin Res Ed). 1984 May;288(6430):15979. Available from: http:// www.ncbi.nlm.nih.gov/pmc/ articles/PMC 1441225/pdf/bmjcred00502-0041.pdf https://doi. org/10.1136/bmj.288.6430.1597 PMID:6426658

2. Buckman R. How to break bad news. A guide for health care professionals. Baltimore: Ed. John Hopkins; 1992. https://doi. org/10.3138/9781487596989.

3. Comunicando malas noticias en Medicina: recomendaciones para hacer de la necesidad virtud. Med. Intensiva v.30 n.9 Barcelona dic. 2006.

4. García W, Lara A, Guevara, et al. Cómo se dan las malas noticias de enfermedad terminal por un grupo médico no especializado en cuidados paliativos. Revista Mexicana de Anestesia, 31 (1), 9-14.2008.

5. Sobrino López A. Comunicación de malas noticias. Semin Fund Esp Reumatol 2008, 09 111-22. Disponible en: http://www.elsevier.es/es/ revistas/seminarios-fundaciona\%C3\%B1olareumatologia-274/ comunicacion-malas-noticias13120139-revisiones-2008

6. Rubistein E. Giuidice C. La comunicación de malas noticias. En: RUBISTEIN Medicina Familiar y Práctica ambulatoria. 2006 (36): 293.

7. Berro Rovira G. La Relación Médico Paciente (RMP) y su actual encuadre legal. Biomedicina 2009, 2: 16-23. http:// www.um.edu.uy/docs/revista- biomedicina_nov_dic\%202009/ bio.pdf (Revisado noviembre, 2011)

8. Libro 'Cómo dar malas noticias en medicina' Dr Marcos Gómez Sancho, 2016,35-74.

9. García F. Comunicando malas noticias en Medicina: recomendaciones para hacer de la necesidad virtud. Med Intensiva. 2006;30(9):452-9. https://doi.org/10.1016/S02105691(06)74569-7.

10. Comunicando malas noticias en la Unidad de Terapia Intensiva. Revista de la Asociación Mexicana de Medicina Crítica y terapia Intensiva. Vol. XXI, Núm. 4 / Oct.-Dic. 2007 pp 194-199.

11. Comunicando malas noticias en Medicina: recomendaciones para hacer de la necesidad virtud. Med. Intensiva v.30 n.9 Barcelona dic. 2006. 